\title{
Hydrocode modeling of the Sierra Madera impact structure
}

\author{
Tamara J. GOLDIN ${ }^{*}$, Kai WÜNNEMANN ${ }^{2}$, H. Jay MELOSH ${ }^{3}$, and Gareth S. COLLINS ${ }^{4}$ \\ ${ }^{1}$ Department of Geosciences, The University of Arizona, Tucson, Arizona 85721, USA \\ ${ }^{2}$ Museum für Naturkunde, Humboldt Universität zu Berlin, Invalidenstrasse 43, 10115 Berlin, Germany \\ ${ }^{3}$ Lunar and Planetary Laboratory, The University of Arizona, Tucson, Arizona 85721, USA \\ ${ }^{4}$ Impacts and Astromaterials Research Centre, Department of Earth Science and Engineering, \\ Imperial College London, London SW7 2AZ, UK \\ ${ }^{*}$ Corresponding author. E-mail: tgoldin@geo.arizona.edu
}

(Received 28 September 2005; revision accepted 08 September 2006)

\begin{abstract}
We present the first hydrocode simulations of the formation of the Sierra Madera structure (west Texas, USA), which was caused by an impact into a thick sedimentary target sequence. We modeled Sierra Madera using the iSALE hydrocode, and here we present two best-fit models: 1) a crater with a rim (final crater) diameter of $\sim 12 \mathrm{~km}$, in agreement with previous authors' interpretations of the original structure, and 2 ) a crater $\sim 16 \mathrm{~km}$ in diameter with increased postimpact erosion. Both models fit some of the geologic observational data, but discrepancies with estimates of peak shock pressure, extent of deformation, and stratigraphic displacement remain. This study suggests that Sierra Madera may be a larger crater than previously reported and illustrates some of the challenges in simulating impact deformation of sedimentary lithologies. As many terrestrial craters possess some amount of sedimentary rocks in the target sequence, numerical models of impacts into sedimentary targets are essential to our understanding of target rock deformation and the mechanics of crater formation.
\end{abstract}

\section{INTRODUCTION}

There are three main branches of impact studies, each of which contributes to our understanding of impact crater formation:

1. Observational studies of terrestrial craters include both geologic and geophysical approaches and provide information about the final crater structure and the conditions experienced by the target rocks. Such studies can provide insight into the results of a hypervelocity impact into sedimentary strata and suggest dynamic models of crater formation, but direct observation of terrestrial impact crater formation is (fortunately) difficult.

2. Experimental studies allow us to look at the underlying processes and physics of crater formation. Experiments have been performed in a range of sedimentary-like target materials, but the small scale of these experiments limits their applicability to larger complex crater formation.

3. Numerical modeling is essential to our understanding of hypervelocity impacts: using experimental knowledge, we can simulate larger craters to establish physically plausible mechanisms for crater formation. Comparing the results of such simulations with observational constraints serves to validate the numerical model as well as test dynamic models of crater formation suggested by observation.

Many terrestrial impact structures were formed in sedimentary target lithologies to some degree. Some impacts, such as Brent, Manicouagan, and Sudbury, occurred in crystalline basement rocks with little or no overlying sedimentary strata. Other impacts, such as Ries and Haughton, encountered a target sequence with more substantial sedimentary components. Although impacts into either wholly crystalline targets or targets with sediments overlying crystalline basement have been modeled previously (i.e., Ries [Wünnemann et al. 2005], Bosumtwi [Artemieva et al. 2004], Chicxulub [Collins et al. 2002; Ivanov 2005], Chesapeake Bay, [Crawford and Barnouin-Jha 2004; Collins and Wünnemann 2005], Lockne [Shuvalov et al. 2005], Upheaval Dome [Kenkmann et al. 2005]), structures with little or no involvement of the crystalline basement have received less attention. The Sierra Madera impact structure is of interest to numerical modelers because it occurred in a sedimentary sequence $5.5 \mathrm{~km}$ thick (Wilshire et al. 1972) and 


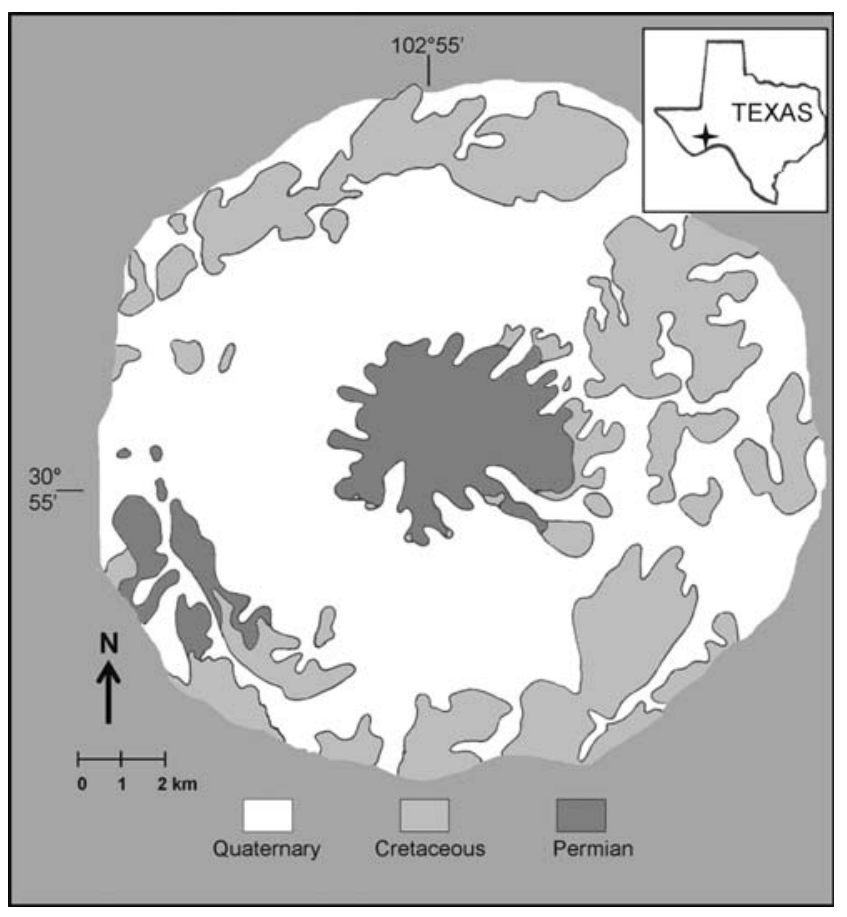

Fig. 1. A generalized geologic map of the Sierra Madera structure. Although much of the structure is buried by Quaternary deposits (white), outcrops of Permian (dark gray) and Cretaceous (light gray) rocks are evident in both the central hills (exposed central uplift) and the outer hills. Wilshire et al. (1972) report little stratigraphic deformation beyond the outer hills (outer shaded region). The inset shows the location of Sierra Madera in west Texas. Based on Howard et al. (1972) and Wilshire et al. (1972).

did not involve any crystalline basement rock. This alone is not unique as many craters in the USA (e.g., Crooked Creek, Flynn Creek, Middlesborough, Wells Creek, Kentland, etc.) formed in purely sedimentary targets, but Sierra Madera is also well exposed and has been the focus of detailed geologic investigations, providing observational data with which to validate the models.

Numerical modeling of impacts into primarily sedimentary target sequences allows us to examine the role such lithologies play in target deformation and test the ability of hydrocodes, through comparisons with observations, to accurately reflect the rheology of sedimentary targets under extreme pressure and temperature conditions. Unfortunately, simulating impacts into sedimentary rocks poses major difficulties. Few reliable equations of state (EoS) for sedimentary materials have been established, and most impact codes do not include the effect of porous compaction on the passage of the shock wave, which can be significant in some sedimentary materials. These factors are important in the early stages of an impact when the impactor and proximal target are rapidly compressed and decompressed. Simulations employing an inadequate EoS or neglecting the effect of porosity can lead to incorrect pressure, temperature, and phase predictions during shock compression and release.
However, while such errors may substantially affect estimates of the volume of vapor and melt produced, and the proportion of material ejected as part of the vapor plume, they likely have a minor effect on the final modification stage of crater formation, which has a more profound influence on the final crater structure and is the main concern of this paper.

More importantly for the accurate modeling of final crater formation, sedimentary rocks exhibit a much wider variation in strength properties than crystalline rocks. Sedimentary materials can be anything from very weak, unlithified, water-saturated sediments that flow in a fluid-like manner when deformed, to strong, dry, nonporous limestone or dolomite rocks that fracture and deform in the same way as crystalline rocks, with the added complication of layering in sedimentary rocks providing pre-existing planes of weakness. Moreover, sedimentary stratigraphy, which can be very heterogeneous, presents a challenge to modelers in terms of the strength algorithm and computational resolution required. The first hydrocode simulations of a meteorite impact (i.e., Bjork 1961) were limited to impact into a strengthless medium (fluid). This is sufficient for modeling the initial contact, compression, and excavation stages of crater formation, but fails to accurately portray the final stage of crater collapse, which depends on both gravity and target rock strength (Melosh 1989). The incorporation of material strength and rheologic models into hydrocodes (e.g., Dienes and Walsh 1970; Roddy et al. 1980; Ivanov et al. 1997) allows us to simulate the final stage of crater formation resulting in crater morphologies typical of complex and simple craters. The strength model is parameterized by several physically meaningful terms whose influence on crater formation can be studied to develop a preliminary model of impact crater formation in a sedimentary target.

In this paper, we present the results from hydrocode modeling of the Sierra Madera impact. Our goal is to obtain a better understanding of the formation of the observed structure with models employing realistic parameters and to test the ability of our current hydrocode to reproduce sedimentary target deformation. We also show how geologic observation and numerical modeling can be effectively combined toward a better understanding of an impact crater. Although impact modeling has become an important field of modern impact cratering studies (Pierazzo and Collins 2003), Sierra Madera has not previously been the subject of such models.

\section{GEOLOGY}

The Sierra Madera structure (Pecos County, Texas, USA) (Fig. 1) is the result of a Late Cretaceous or Early Tertiary impact into a thick carbonate target sequence (Wilshire et al. 1972). Impact breccias, shocked quartz, and shatter cones offer petrologic evidence for an impact origin and provide shock pressure estimates (Wilshire et al. 1972). The crater is 


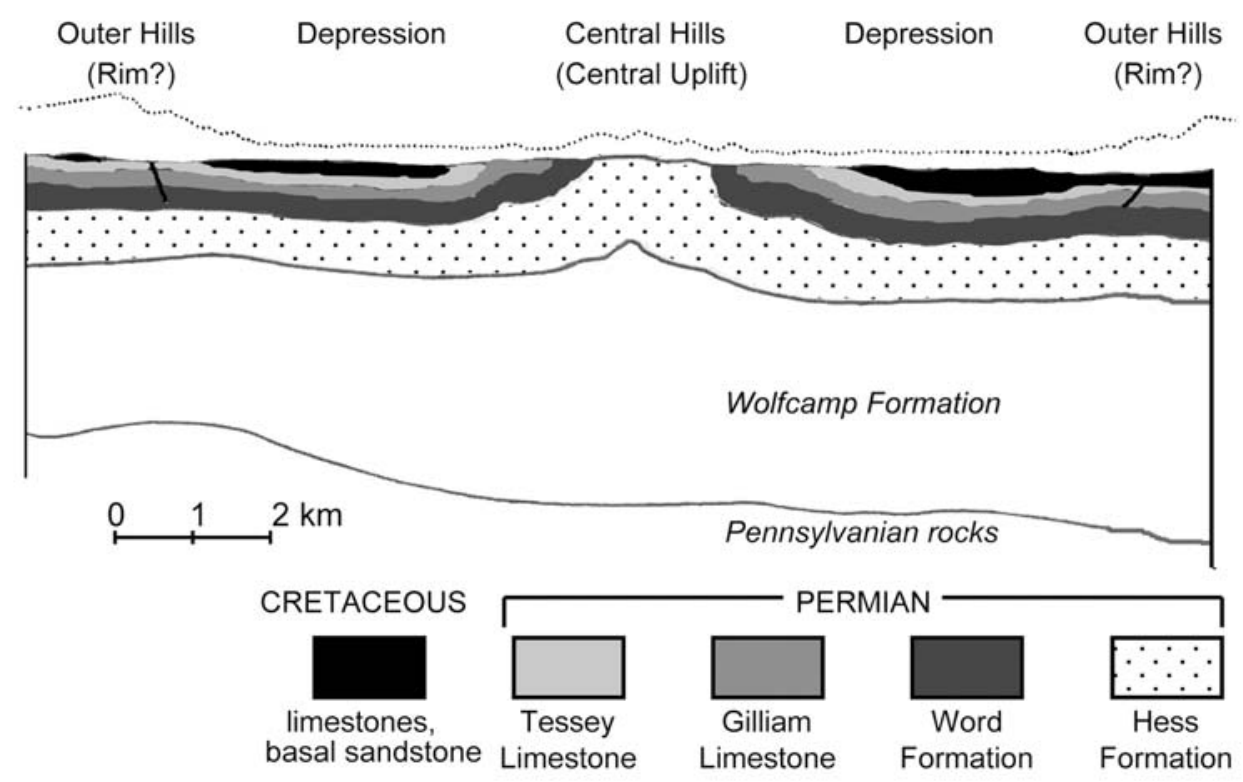

Fig. 2. A generalized cross-section of the present Sierra Madera structure showing the major stratigraphic units involved in impact deformation and their relative displacements. The dotted line shows the interpretation by Howard et al. (1972) of the pre-erosional crater profile. The central hills correspond with the central uplift and the outer hills correspond with the remnant crater rim. This interpretation suggests a final rim-to-rim crater diameter of $\sim 12 \mathrm{~km}$. Based on Howard et al. (1972).

complex, with an intensely folded and faulted central uplift. The present eroded structure consists of central hills $\sim 180 \mathrm{~m}$ high and $\sim 5 \mathrm{~km}$ in diameter exposing uplifted Permian strata, a surrounding structural depression floored by Lower Cretaceous strata, and an $\sim 11.5 \mathrm{~km}$ diameter concentric ring of low hills topped by Lower Cretaceous strata and cut by inward-facing normal faults. The diameter of the crater has been interpreted as $12-13 \mathrm{~km}$, based on the observed outer limit of deformation and analogies with lunar craters, and assuming the outer hills to represent the eroded rim (Wilshire et al. 1972; Howard et al. 1972). Wilshire et al. (1972) interpret this diameter as a rim diameter. However, it is actually an apparent diameter (Turtle et al. 2005), as it is inferred from the diameter of the outermost concentric impact deformation exposed in the eroded structure. Determining the rim diameter of a terrestrial crater is often difficult due to postimpact erosion and the unclear correlation between structural features exposed by erosion and those observable in a fresh crater (Turtle et al. 2005). Whether this $12 \mathrm{~km}$ apparent diameter is related to the rim diameter depends on the genetic relationship between the fault-bounded outer hills and the original rim, something that field studies alone cannot discern.

Sierra Madera is a particularly good subject for modeling because there is a wealth of observational data to compare with our model results. Despite subaerial erosion of the original crater, the semi-arid environment of the region allows for easy access to outcrops unimpeded by vegetation. The structure has been extensively drilled, particularly in the folded and faulted outer hills and central uplift. The geology of the Sierra Madera structure has been mapped in detail based on exposures and drill cores, most recently in the early 1970s (Wilshire et al. 1972). Early mapping efforts focused mainly on the Sierra Madera hills (the central uplift), but later studies recognized the structural depression and outer hills as parts of the impact structure (Wilshire et al. 1972). Despite significant advances in the field of impact cratering since the 1970s, Sierra Madera has unfortunately not been revisited for updated surveys. Most of the geologic information used in this study is taken from the Wilshire et al. (1972) USGS Professional Paper \#599-H, which is the most complete and recent source of information on Sierra Madera.

Strata exposed at Sierra Madera are of Early Permian through Early Cretaceous age. These include the Hess Formation (average thickness $\sim 800 \mathrm{~m}$ ), a regressive sequence of limestones and dolomites with interbedded shales and sandstones; the Word Formation (average thickness 200 m), a shelf-facies deposit of limestone and dolomite; the Gilliam Limestone (average thickness $\sim 250 \mathrm{~m}$ ), a bedded dolomite; the Tessey Limestone (average thickness $<100 \mathrm{~m}$ ), containing dolomite and reef-related dolomite breccias; the basal Cretaceous sandstone ( $\sim 20 \mathrm{~m}$ thick); and Early Cretaceous limestone units which were subsequently exposed above sea level (Wilshire et al. 1972). The generalized cross-section in Fig. 2 shows the relative positions and thicknesses of these formations. In a general sense, the Permian target rock sequence consists of predominantly dolomites with some interbedded sandstones and is overlain by Lower Cretaceous limestones, most of which have since eroded away. Compared to other units within the central uplift, the Lower Cretaceous 
rocks are rarely brecciated and any such breccias contain limestone dykes and contorted lamellae within limestone clasts. Shatter cones are not found in these formations either. These features suggest that the Lower Cretaceous rocks were not completely consolidated at the time of impact (Wilshire et al. 1972), and thus might have been less resistant to shear failure (smaller yield strength) and have a lower density (less compaction/cementation) than the underlying Permian strata. The depth of deformation beneath the crater, as seen in drill cores, is $1.8-2.4 \mathrm{~km}$, dying out in the lowermost Permian (Wolfcamp Formation) (Wilshire et al. 1972).

As expected for a terrestrial crater of this size (Melosh 1989), Sierra Madera has a complex structure with a central uplift. As the crater is eroded, it is not possible to prove with observations whether Sierra Madera originally had a central peak after its formation (Turtle et al. 2005). The exposed central uplift, defined as the zone of uplifted strata, is $6-8 \mathrm{~km}$ in diameter and the oldest exposed rocks, from the Hess Formation of Lower Permian age, show $1.2 \mathrm{~km}$ of stratigraphic uplift. This zone has been folded and faulted and the rocks have been pervasively brecciated to produce both monomict and polymict breccias. Deformation increases towards the center of the structure. The surrounding structural depression is $\sim 1 \mathrm{~km}$ in width and is filled by Quaternary alluvium. The stratigraphy shows evidence of disturbance with dips up to vertical and some faulting (Wilshire et al. 1972). The outer hills, occupying an annular zone $\sim 0.8 \mathrm{~km}$ wide, expose Upper Permian and Lower Cretaceous strata, the latter of which shows $<30 \mathrm{~m}$ of stratigraphic uplift. The strata are cut by inward-facing concentric normal faults and deformed by folds whose axes are also concentric to the structure (Wilshire et al. 1972). It has been inferred in previous studies (Howard et al. 1972; Wilshire et al. 1972) that the outer hills of Sierra Madera represent strata folded beneath the original $12 \mathrm{~km}$ diameter crater rim, which have since been exposed via erosion. Scaling to the dimensions of other lunar and terrestrial craters suggests $\sim 600 \mathrm{~m}$ of postimpact erosion (Wilshire et al. 1972).

\section{Shock Pressures}

In addition to geologic observations, there is another parameter documented at Sierra Madera that can be compared to model results: peak shock pressure. Shock deformation products, such as breccias, shatter cones, and planar deformation features in mineral grains, are associated with certain shock pressure ranges determined from experimental shock studies in crystalline and sedimentary rocks (Grieve et al. 1996; French 1998). Wilshire et al. (1972) measured 1400 sets of planar elements and cleavages observed in shock-deformed quartz grains from sandstone and conglomerate units at Sierra Madera. Plane orientations, using experimental results of Hörz (1968) and Müller and Défourneaux (1968), indicate the following shock pressures, which in general increase towards the structure's center: 1) $>20 \mathrm{GPa}$ in mixed breccias near the structure's center, 2) $>10 \mathrm{GPa}$ in in situ rocks near the center, and 3) $>5 \mathrm{GPa}$ in rocks near the edge of the central uplift (Wilshire et al. 1972). Shatter cones surrounding the central uplift 2-4 km from the structure's center (Howard and Offield 1968) support these assumptions, as shatter cones are believed to result from shock pressures of 2-10 GPa (Roddy and Davis 1977; French 1998). It should be noted that the mixed breccias sometimes occur along faults and commonly contain clasts of monolithic breccia, shatter cones, and clasts from different stratigraphic levels, suggesting the mixed breccias are allochthonous and were emplaced during formation of the central uplift (Wilshire et al. 1972). Thus, the intense shock deformation experienced by these mixed breccia dykes do not necessarily reflect the peak shock pressures of the surrounding rocks.

\section{HYDROCODE MODELING}

To reproduce the observed target deformation, crater morphology, and pressure distribution of the Sierra Madera structure, we performed hydrocode simulations of the impact event using the axisymmetric finite-difference 2-D hydrocode iSALE (impact SALE) (Wünnemann et al. 2006). iSALE is based on the SALE (Simplified Arbitrary LagrangianEulerian) hydrocode (Amsden et al. 1980), and consolidates into one algorithm many aspects of the family of multimaterial, multi-rheology extensions to the original code now being used within the impact community (e.g., SALEB, SALE-3MAT, SALES-2). For the modeling of crater formation, accurately simulating the material response to large stresses is crucial. The strength model used in this study was first introduced to the code by Ivanov et al. (1997). It includes pressure- and temperature-dependent strength, shear failure, strain softening, brittle and ductile deformation (Collins et al. 2004), and acoustic fluidization (Melosh and Ivanov 1999; Wünnemann and Ivanov 2003).

We approximated the target stratigraphy using two material layers, where material properties may vary according to the different lithologies (Table 1): a denser lower layer representing Permian and older carbonates overlain by a less dense upper layer representing unconsolidated Lower Cretaceous limestones, which Wilshire et al. (1972) noted to have experienced less cementation and compaction. Our simulations employed rock strength parameters reasonable for limestone as compared with laboratory data for limestone and dolomite (Lundberg 1968; Fredrich et al. 1990; Lockner 1995). We also explored a range of possible strength parameters for both target layers, varying the damaged friction coefficient between 0.4 and 0.8 .

To calculate the thermodynamic state of the materials we used the Tillotson EoS (Tillotson 1962) with the temperature extension by Ivanov et al. (2002). Both layers use identical 
Table 1. Input parameters for the two best-fit Sierra Madera numerical models.

\begin{tabular}{lll}
\hline Input parameter & Small crater model & Large crater model \\
\hline Impactor & & \\
Diameter & $680 \mathrm{~m}$ & $1000 \mathrm{~m}$ \\
Impact velocity & $17.8 \mathrm{~km} / \mathrm{s}$ & $17.8 \mathrm{~km} / \mathrm{s}$ \\
Material & Limestone & Limestone \\
Upper layer & & \\
Thickness & $1000 \mathrm{~m}$ & $1500 \mathrm{~m}$ \\
Material & Limestone & Limestone \\
Density & $2500 \mathrm{~kg} / \mathrm{m}^{3}$ & $2500 \mathrm{~kg} / \mathrm{m}^{3}$ \\
Friction coefficient (undamaged) & 2.0 & 2.0 \\
Friction coefficient (damaged) & 0.4 & 0.6 \\
Cohesion, strength at $P=0$ (undamaged) & $50 \mathrm{MPa}$ & $50 \mathrm{MPa}$ \\
Cohesion (damaged) & $0.1 \mathrm{MPa}$ & $0.1 \mathrm{MPa}$ \\
von Mises plastic limit, strength at $P=\infty$ & $650 \mathrm{MPa}$ & $650 \mathrm{MPa}$ \\
Lower layer & & \\
Material & Limestone & Limestone \\
Density & $2700 \mathrm{~kg} / \mathrm{m}^{3}$ & $2700 \mathrm{~kg} / \mathrm{m}^{3}$ \\
Coefficient of internal friction & 2.0 & 2.0 \\
Friction coefficient (damaged) & 0.8 & 0.6 \\
Cohesion (undamaged) & $50 \mathrm{MPa}$ & $50 \mathrm{MPa}$ \\
Cohesion (damaged) & $0.1 \mathrm{MPa}$ & $0.1 \mathrm{MPa}$ \\
von Mises plastic limit, strength at $P=\infty$ & $650 \mathrm{MPa}$ & $650 \mathrm{MPa}$ \\
Mesh setup & & \\
Number of cells $n x$ (radial) & $640 \mathrm{cells}$ & \\
Number of cells $n y$ (vertical) & $540 \mathrm{cells}$ & \\
Number of extended cells top, right, bottom & $30,70,70$ & \\
Tracer interval (high resolution area) & $25 \mathrm{~m}$ & \\
\hline
\end{tabular}

EoS parameters (standard Tillotson limestone). It should be noted that, although the majority of the target rocks are dolomite, the target parameters are based on limestone as there is not currently a Tillotson or ANEOS EoS for dolomite.

An acoustic fluidization model was employed to explain the temporary strength loss of the impacted target rocks necessary to produce the postcollapse crater morphology. For more details about the temporary fluidization of fractured rocks due to a short-wavelength acoustic field, see Melosh (1979), Melosh and Ivanov (1999), and Wünnemann and Ivanov (2003). The behavior of the acoustically fluidized target is controlled by the viscosity of the fluid material and the decay time of the acoustic vibrations (Melosh and Ivanov 1999). In iSALE, these parameters are defined by simple linear scaling laws suggested by Wünnemann and Ivanov (2003), which successfully reproduce the depth/diameter relations of craters on the Moon. On the Earth, as different materials exhibiting a large variety of thermodynamic and constitutive properties are usually involved in crater formation, particularly in sedimentary targets, it is not clear whether scaling of these parameters is applicable. In this study, some deviations from the original scaling parameters
Table 2. Acoustic fluidization parameters for the two bestfit Sierra Madera models.

\begin{tabular}{lll}
\hline Parameter & Small crater model & Large crater model \\
\hline$\gamma_{\beta}$ & 300 & 300 \\
$\gamma_{\eta}$ & 0.003 & 0.003 \\
Viscosity $\eta$ & $14.1 \mathrm{MPa} \mathrm{s}$ & $20.0 \mathrm{MPa} \mathrm{s}$ \\
Decay time $T_{\text {dec }}$ & $21.0 \mathrm{~s}$ & $30.0 \mathrm{~s}$ \\
\hline$\gamma_{\beta}$ and $\gamma_{\eta}$ are dimensionless scaling parameters (Wünnemann and Ivanov \\
$2003)$.
\end{tabular}

(Ivanov and Artemieva 2002; Wünnemann et al. 2005) were required in order to achieve a good fit. The acoustic fluidization parameters employed for the Sierra Madera models are shown in Table 2.

Two possible scenarios were investigated (Table 1): 1) a smaller final crater with a rim (final crater) diameter of $12 \mathrm{~km}$ and $\sim 700 \mathrm{~m}$ of erosion, consistent with previous interpretations of the structure, and 2) a larger final crater with a rim diameter of $16 \mathrm{~km}$ and increased $(\sim 1.2 \mathrm{~km})$ erosion of thicker Cretaceous strata. Both models employ a projectile impact velocity of $17.8 \mathrm{~km} / \mathrm{s}$, which is the average impact velocity between asteroids that cross the Earth's orbit (NEOs) and the Earth's surface (Bottke et al. 1994). Scaling laws were 


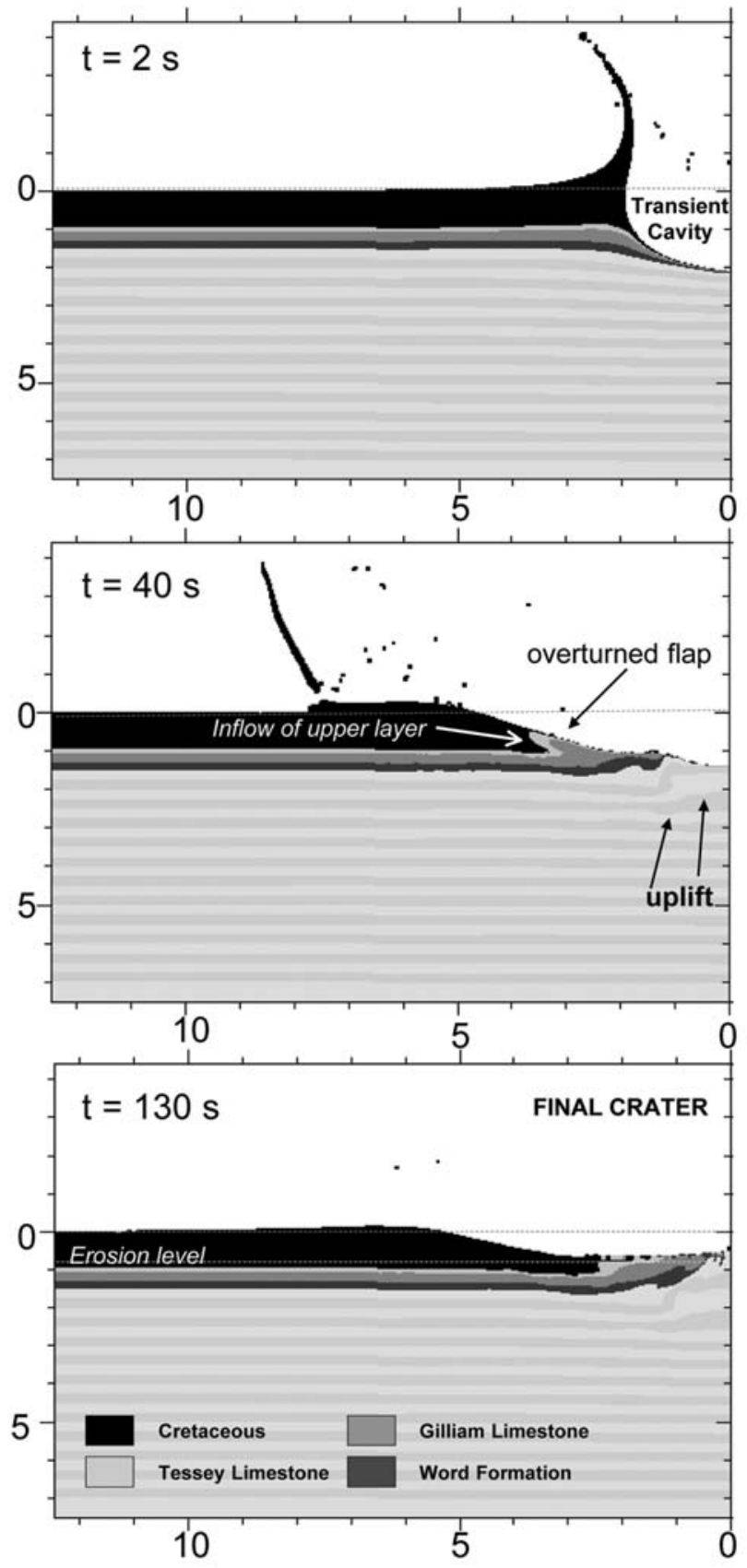

Fig. 3. A series of snapshots from our best-fit smaller crater model illustrating the formation of a crater $12 \mathrm{~km}$ in diameter. All axes are in kilometers. A transient crater $8 \mathrm{~km}$ in diameter forms $2 \mathrm{~s}$ after impact. Further excavation of the crater at the transient crater rim results in the formation of an overturned flap. After $40 \mathrm{~s}$, we observe the formation of the central uplift and the collapse of the crater rim, resulting in the inflow of the Upper Cretaceous layer and partial unfolding of the overturned flap. The final frame shows the final crater profile and the hypothesized postimpact erosion level. All frames plot the displacement of tracer particles, which were originally arranged in horizontal layers and shaded to correspond with relevant stratigraphic units. All stratigraphic units are included in the model as the lower material layer, with the exception of the Cretaceous, which is modeled as the upper material layer. used to estimate the projectile parameters (Schmidt and Housen 1987). The smaller crater was modeled using a projectile of radius $340 \mathrm{~m}$ striking a target with an upper layer thickness of $1 \mathrm{~km}$; the larger crater was modeled using a projectile radius of $500 \mathrm{~m}$ and an upper layer thickness of $1.5 \mathrm{~km}$. In both models, the density of the upper layer was less than the lower layer (see Table 1). In the best-fit smallercrater model, the upper layer was also prescribed weaker strength properties compared to the lower layer. Both models employed meshes of equal dimensions and cell sizes. Models were run from the moment of projectile impact to $130 \mathrm{~s}$ after impact, at which point little further deformation was recorded. Maximum resolution in both models was $25 \mathrm{~m} \mathrm{(14}$ and 20 cells per projectile radius for the small- and largecrater models, respectively); simulations with lower resolution produced craters with nearly identical morphologies. We ran numerous models of both the smaller and larger crater scenarios, testing a range of strength and density parameters. The two models presented here are the models for each scenario that best fit the observational data available for Sierra Madera.

\section{RESULTS}

Both the best-fit smaller crater and larger crater models, taking into account erosion of all but $100-300 \mathrm{~m}$ of Cretaceous strata, reproduce the observed crater geology fairly well. The smaller crater model (Fig. 3) produces a transient crater $\sim 8 \mathrm{~km}$ in diameter and a final crater with a rim $12 \mathrm{~km}$ in diameter. Erosion of $\sim 700 \mathrm{~m}$ of Cretaceous strata reveals a crater profile similar to that which is observed. Comparisons with the simplified geologic cross-section (Fig. 2) show that the model predicts outcropping of the various stratigraphic units where they are observed, including exposure of the Hess Formation in the central uplift. The modeled pressure contours agree with those estimated from shocked quartz grains. Pressures range from $>20 \mathrm{GPa}$ at the center of the structure to $>5 \mathrm{GPa}$ at the outskirts of the central uplift. Shock pressures in the rocks draping the central uplift exceed $40 \mathrm{GPa}$, but these are mostly removed by subsequent erosion.

The best-fit smaller crater model shows two major inconsistencies with observational data from Sierra Madera. Following the stages of crater formation (Fig. 3), we see that the Permian strata are overturned during the excavation of the transient cavity. As the transient crater rim collapses, the overturned stratigraphy is pushed inwards towards the rising crater center. The weaker Cretaceous layer flows inward more readily than the Lower Permian units, reducing the overturning. However, even after erosion, the model still predicts inversion of the uppermost Permian strata (Tessey Limestone) at the edges of remaining central uplift, which is inconsistent with geologic maps and cross-sections (Wilshire et al. 1972) that show no overturned stratigraphy. We found 
no alternative material strength or acoustic fluidization input parameters that could further reduce the overturning without creating new inconsistencies with observations. Secondly, the smaller-crater model produces a smaller central uplift than observed. The oldest exposed rocks (Hess Formation) are uplifted $\sim 1 \mathrm{~km}$, slightly less than the $1.2 \mathrm{~km}$ of uplift observed. More importantly, the modeled posterosion central uplift's diameter $(\sim 5 \mathrm{~km})$ is less than the observed width of uplifted strata $(\sim 8 \mathrm{~km})$. The diameter of the Hess Formation exposed in the central hills, as predicted by the model, is $\sim 1 \mathrm{~km}$; in the field, the Hess is at least $1.6 \mathrm{~km}$ wide (Wilshire et al. 1972).

The best-fit larger crater model (Fig. 4) produces a transient crater $\sim 10 \mathrm{~km}$ in diameter and a final crater with an $\sim 16 \mathrm{~km}$ rim diameter. Erosion of $\sim 1.2 \mathrm{~km}$ of Cretaceous strata also reveals a structure similar to Sierra Madera. As in the previous model, an overturned flap is formed, but, because of the increased synimpact Cretaceous thickness compared to the smaller-crater model, it is overridden by the inward-flowing Upper Cretaceous layer during crater collapse. Any remaining overturned stratigraphy is small and would mostly be removed by erosion. The geometry of the central uplift, taking erosion into account, is in better agreement with the observed geology, with respect to both the amount of uplift and uplift diameter. The diameter of the modeled exposed Hess Formation $(\sim 2 \mathrm{~km})$ is closer to the observed outcroppings. The diameter of the posterosion "rim" (where the remaining strata are upwarped) is $\sim 12 \mathrm{~km}$, which is consistent with the location of the low outer hills at Sierra Madera.

The geometric agreement between the larger-crater model and observations is not exact. In the models, the stratigraphy surrounding the central uplift shows a pronounced depression (Fig. 4). Despite previous authors' labeling this zone the "structural depression" (Wilshire et al. 1972, etc.), the geologic cross-sections (Fig. 2) indicate only a slight stratigraphic depression. Furthermore, a more energetic impact creates additional potential inconsistencies between model results and observational constraints. The modeled pressure contours (Fig. 5b) indicate that rocks exposed in the central uplift experienced pressures exceeding $40 \mathrm{GPa}$, which is higher than previously estimated maximum shock pressures based on geologic indicators of shock exposure. Even taking erosion into account, the model predicts peak pressures exceeding $40 \mathrm{GPa}$. Additionally, the extent of damage is much greater for a larger impact (Fig. 5a). No evidence for impact-related deformation has been described beyond the outer hills or deeper than a few kilometers. This is a problem, as impact deformation is expected to extend beyond the crater rim. It is also uncertain whether the modified assumptions used in the larger crater model are reasonable. Whether a $1.5 \mathrm{~km}$ thick Cretaceous unit is realistic is difficult to ascertain given the poor constraints on the crater's age and the fact that the Cretaceous is overlain by an erosional unconformity throughout the region.

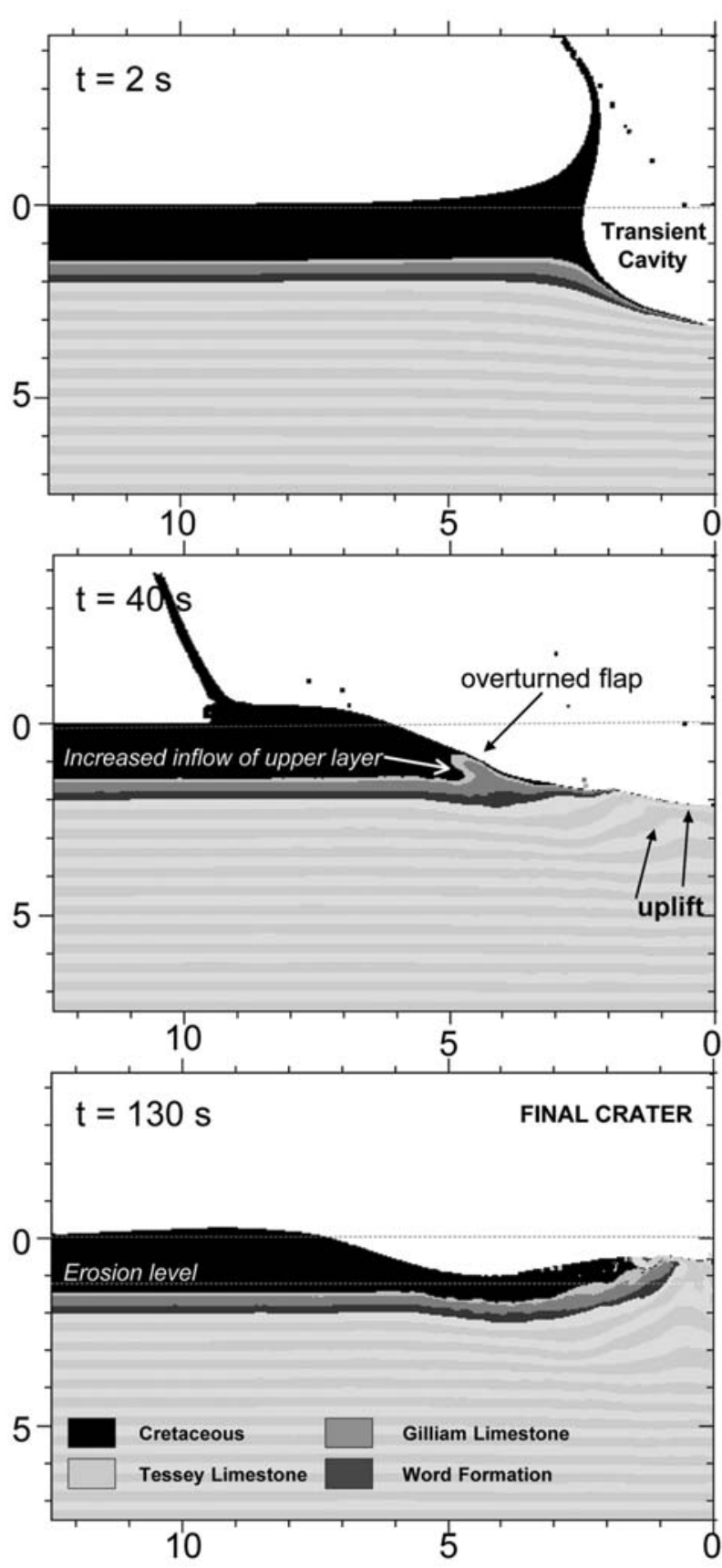

Fig. 4. Similar to Fig. 3, but illustrating the formation of a crater $16 \mathrm{~km}$ in diameter in our best-fit larger crater model. A transient crater $10 \mathrm{~km}$ in diameter forms $2 \mathrm{~s}$ after impact, and subsequently an overturned flap forms. After $40 \mathrm{~s}$, we can observe the formation of the central uplift and the collapse of the crater rim. The inflow of the Cretaceous layer unfolds the overturned flap entirely. Note the relative thicknesses of the Cretaceous layer as compared with Fig. 3.

\section{HOW BIG IS SIERRA MADERA?}

Neither model can be eliminated at this stage. Figure 5 shows a comparison of the two models, including the contours for pressure and plastic strain. Models of the $12 \mathrm{~km}$ 

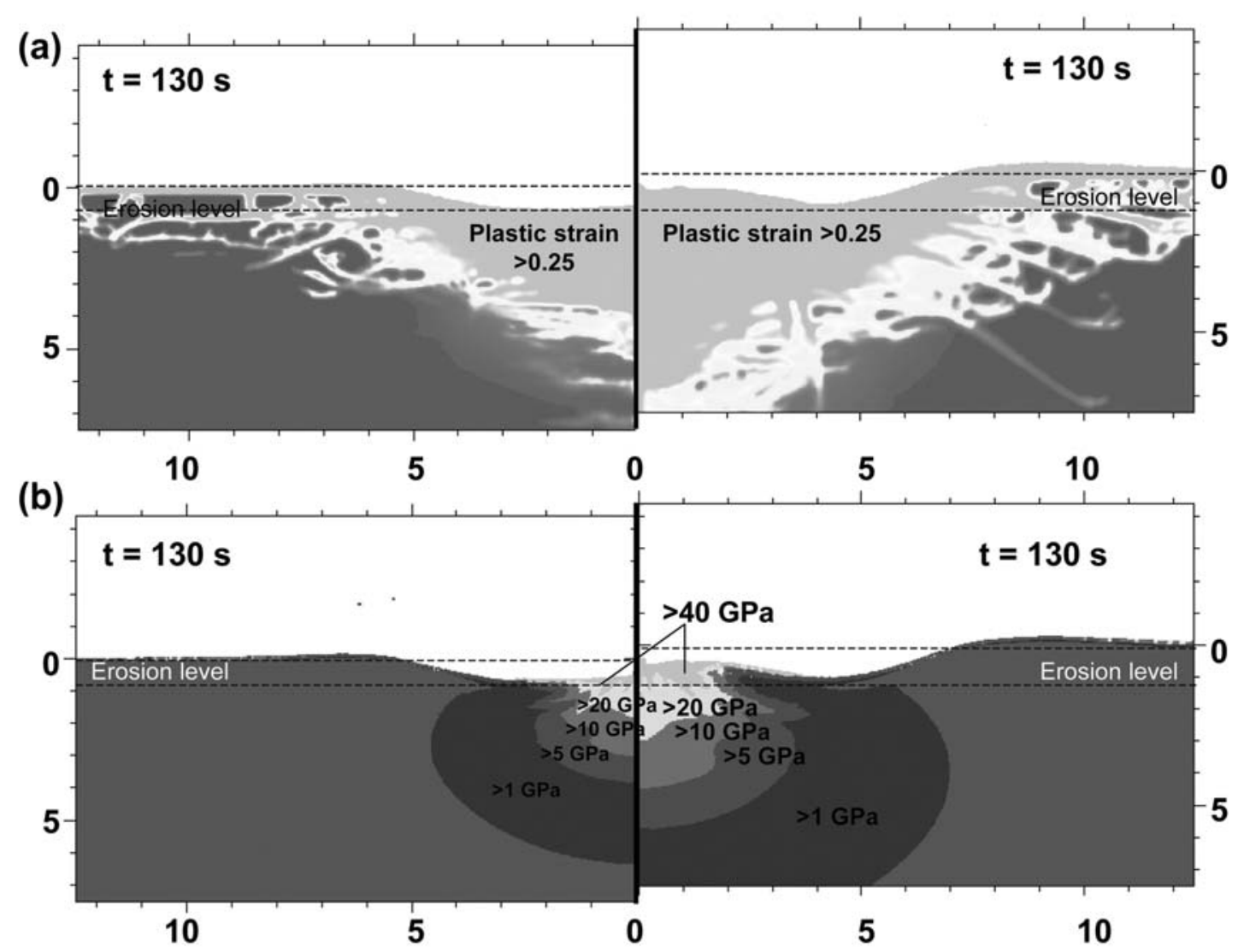

Fig. 5. Final crater cross-sections comparing the best-fit larger crater (right) and smaller crater (left) models. The two models are aligned according to hypothesized erosion level and all axes are in $\mathrm{km}$. a) Plastic strain contours. b) Maximum pressure contours.

diameter crater fit previous interpretations of Sierra Madera, but do not produce a vigorous enough collapse of the transient crater to explain the observed crater geometry. Models of the $16 \mathrm{~km}$ diameter crater better reproduce the crater geometry, but fail to agree with previous workers' interpretations and observations of the extent and degree of deformation. Both scenarios produce structures similar to Sierra Madera, but both also have shortcomings. This modeling effort suggests a series of observational and numerical tests necessary to confront the inconsistencies between the model results and observations, and better determine the true size of Sierra Madera.

\section{Crater Morphology}

It is possible that the overturning of Upper Permian strata in the smaller crater model may exist at Sierra Madera, but was not detected from the single drill core in this region of the crater used in previous mapping efforts (Wilshire et al. 1972). The central uplift has been mapped most thoroughly because its structure is the most complex and thus geologically "interesting." Although unlikely, it is possible that overturning of stratigraphy in the structural depression does exist, but was overlooked. Some targeted field work in this region of the crater can test this possibility. Unfortunately, the lithology of the Tessey Limestone may make field identification of overturning difficult because the formation is mostly block breccia (Wilshire et al. 1972). Even so, further geologic observations in this region of the crater are needed to test whether there is a more pronounced structural depression surrounding the uplift, as seen in the larger-crater model. Improvements to the hydrocode to incorporate more of the heterogeneous characteristics of sedimentary rocks (see below) may eliminate the overturning or central depression problems entirely.

\section{Shock Levels}

The peak pressures predicted by the larger crater model (and to some extent the smaller crater model) are greater than those reported by Wilshire et al. (1972). The discrepancy between modeled and observed shock pressures may be in part due to the limitations of the material model employed in the iSALE hydrocode. The Tillotson EoS for limestone used in this work is not ideal because it does not accurately represent the behavior of the predominantly dolomitic target rocks at Sierra Madera. Unfortunately, there is no available EoS for dolomite, which is often a stronger material than 
(a)

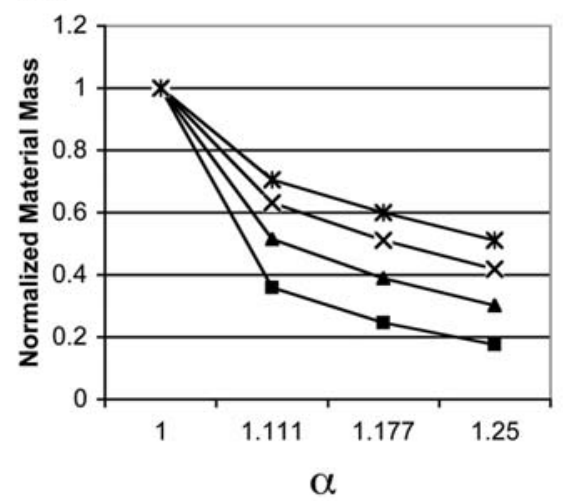

(c)

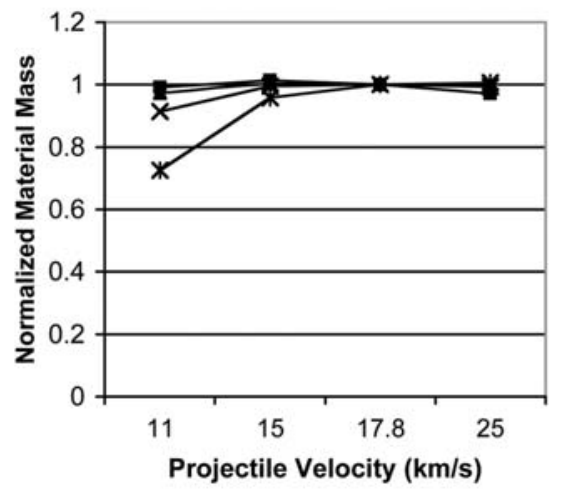

(b)

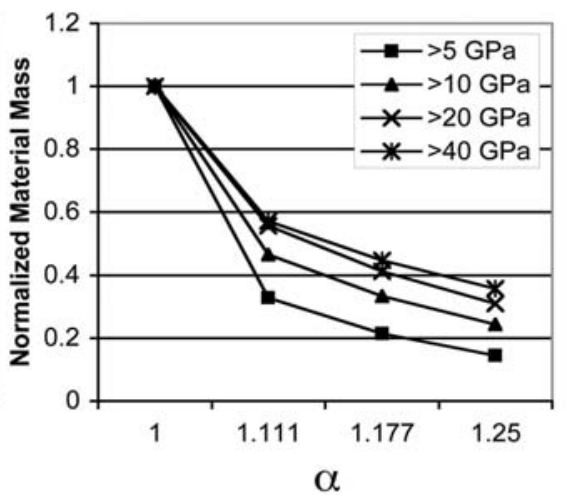

(d)

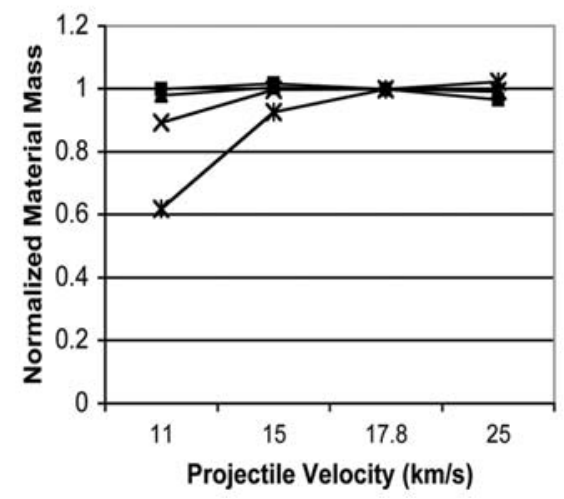

Fig. 6. Mass of target material experiencing shock levels exceeding 5, 10, 20, and $40 \mathrm{GPa}$ versus (a) target rock porosity, normalized to the case of zero porosity $(\alpha=1)$, and (c) projectile velocity, normalized to the average impact velocity $(17.8 \mathrm{~km} / \mathrm{s})$. (b) and (d) show the normalized mass of variously shocked materials remaining after the erosion of $1200 \mathrm{~m}$, with varying porosity and impact velocity, respectively. All other model parameters are identical to those used in the larger crater model.

limestone. Moreover, the Tillotson equation of state does not account for porous compaction, which would greatly reduce the shock pressures predicted by the model, particularly in the Upper Cretaceous limestone layer which is assumed to be more porous than the lower units. Additionally our model assumes an average impact velocity, but a lower velocity might help explain the moderate shock levels observed.

To quantify how target porosity and impact velocity affect modeled peak shock pressures, we performed a series of simulations varying those two parameters (separately) and keeping all other input parameters consistent with the larger crater model. The simulations were run for a model time of $1 \mathrm{~s}$, at which point the main shock wave, which imparts the maximum shock to the target rocks, has passed through the target. The mass of target material at various shock levels was then quantified and normalized to the larger crater model. As the use of labeled tracer particles in the iSALE hydrocode allows us to track the movement of material throughout a simulation, we were able to roughly reconstruct the pressure structure of the final crater (based on the final position of tracers in the larger crater model and using the same initial number and spacing of tracers in each of our simulations as in the larger crater model) and determine the quantity of material remaining after $\sim 1200 \mathrm{~m}$ of erosion. The results from these simulations are plotted in Fig. 6.

Employing the porosity algorithms incorporated into the iSALE hydrocode by Wünnemann et al. (2006), we introduced uniform porosity between 0 and $20 \%(\alpha=1.0$ 1.25 , where $\alpha=1 /[1-\varphi]$ and $\varphi$ is porosity) to both material target layers. Increasing porosity decreases the amount of shocked material for all measured shock levels (Fig. 6a), decreasing, for $\alpha=1.25$, the lowest-shocked materials to $20 \%$ and the highest-shocked materials to $50 \%$ of the nonporous scenario. Considering erosion (Fig. 6b) further reduces the mass of highly shocked material to less than $40 \%$ of that of the nonporous simulation. Of course, the target rock at Sierra Madera was not uniformly porous; the upper unconsolidated layer likely would have had some porosity, but this would have decreased with depth (and increasing compression/ lithification). So the quantity of highly shocked materials produced from impact into two highly porous target layers represents a minimum. Simulations of a nonporous lower layer overlain by a porous upper layer predict less change in shock pressures: when $\alpha=1.25$ in the upper layer, the material mass shocked $>40 \mathrm{GPa}$ is reduced to only $70 \%$ (with erosion, $60 \%$ ) of the entirely nonporous target simulation. 
Porosity decreases the amount of highly shocked material, but does not eliminate it entirely. Even if the entire target was highly porous, this only reduces the mass of shocked material by half and not all of this can be removed by erosion.

Impact velocity was also varied between 11 and $25 \mathrm{~km} / \mathrm{s}$ to quantify the effect of impact velocity on the amount of highly shocked target rock. The projectile size was changed accordingly to produce a $16 \mathrm{~km}$ crater and resolution was adjusted to keep fixed the number of computational cells per projectile radius $(\mathrm{cppr}=20)$. The lowest possible impact velocity for terrestrial craters is $11.2 \mathrm{~km} / \mathrm{s}$, the Earth's escape velocity. It is apparent (Fig. 6c) that decreasing the impact velocity does decrease the mass of material at the $>40 \mathrm{GPa}$ shock level to $\sim 70 \%$ of the mass for an impact velocity of $17.8 \mathrm{~km} / \mathrm{s}$. There is little effect on the moderately shocked materials (5-20 GPa). With erosion (Fig. 6b), the highly shocked material can be further reduced to $60 \%$ of the average impact velocity scenario. Additionally, we tested the effects of a lower impact velocity by modeling Sierra Madera (through all stages of crater formation) using an impact velocity of $12 \mathrm{~km} / \mathrm{s}$. Although the bigger projectile causes broader pressure contours, peak pressures within the central uplift still exceed $40 \mathrm{GPa}$. An anomalously low impact velocity reduces the quantity, but does not remove the problem of highly shocked material.

Adding target rock porosity and employing a low impact velocity in our simulations fails to eliminate the discrepancy between modeled and observed shock pressures. Additionally, the error in estimating the amount of shocked materials at the current model resolution is $<10 \%$ compared with higher resolutions. Recent X-ray powder analysis of carbonate and siliciclastic samples from the central uplift by Huson et al. (2006) indicates moderate shock pressures ( 8 to $30 \mathrm{GPa}$ ). This suggests peak pressures may have been higher than the previous $20 \mathrm{GPa}$ estimates, but does not support the high peak pressures predicted by the larger crater model (although there is some uncertainty in assigning peak pressures to sedimentary target rocks as shock waves pass through porous and fully consolidated materials differently [French 1998]). Observational data from various impact structures in crystalline targets support $>40 \mathrm{GPa}$ shock levels only for craters with rim diameters exceeding $100 \mathrm{~km}$ (Grieve and Cintala 1992). If both our model predictions and the observational data are accurate, then the discrepancy between the two must be explained. Perhaps rocks that have experienced a higher degree of shock are weaker and preferentially eroded. Further studies of the relative ease of erosion of various impact-deformed rocks may clarify this suggestion.

\section{Impact Deformation}

The two models differ in the extent of impact deformation. The smaller model produces zones of damage and strain of similar dimensions to those previously described, while the larger crater suggests deformation of a greater volume of target rock. The lack of impact deformation described beyond $\sim 12 \mathrm{~km}$ in diameter is a serious problem for the larger crater model. In a fresh crater, the region outside the crater rim is blanketed with ejecta and it is unclear how faults exposed at an eroded structure correlate with the original crater structure (Turtle et al. 2005), but the strain calculations from our model (Fig. 5) suggest that the outermost impact deformation is probably not coincident with the original rim. For example, the outermost concentric faults observed at the mid-sized Haughton impact structure impart an apparent crater diameter of $23 \mathrm{~km}$ (Osinski and Spray 2005; Osinski et al. 2005), but Osinski et al. (2005) suggest that these outermost faults lie beyond the crater rim and are only visible due to erosion of the originally overlying ejecta, and estimate the actual rim diameter at $\sim 16 \mathrm{~km}$. Using similar logic, the outermost impact deformation at Sierra Madera should lie outside the original crater; if the diameter of this deformation is indeed $\sim 12 \mathrm{~km}$, then the rim diameter should be even smaller than the models presented here.

One must exercise caution when comparing modeled and observed impact deformation. Previous estimates of impact deformation at Sierra Madera are based on the extent of folding and faulting of the stratigraphy as seen in drill cores (Wilshire et al. 1972). However, stratigraphic displacement is not the best measure of deformation. Beneath the central uplift, for example, much of the stratigraphy which is initially displaced downwards is then uplifted to its original stratigraphic position (Melosh 1989). The net strains experienced by these rocks would be small, even though the total strains experienced may be significant. The iSALE hydrocode calculates both net and total plastic strain (Collins et al. 2004). In the field, only the final (net) strain can be observed; the path-dependent total strain cannot. Hence rocks may be fractured, but not pervasively brecciated or noticeably displaced, and may be overlooked as impact-deformed by geologists. Gravity mapping may help in this debate as a larger crater should be associated with a larger gravity anomaly than a smaller crater due to a greater volume of fractured material with reduced density. Sierra Madera was the subject of gravity and magnetic studies in the 1960s (Van Lopik et al. 1963), but these studies focused on the central uplift only. Transects of the entire structure are needed. Seismic study of Sierra Madera may be a useful geophysical approach as well because the distribution of seismic velocities can also be used to map the extent of the fragmentation zone. Although Wilshire et al. (1972) did use drill cores from outside the outer hills in their mapping effort, this area was not mapped in detail and it is possible the lateral extent of deformation is greater than previously reported. Additional field work outside of the central hills to look for faulting or fracturing of the target stratigraphy may give further insight to this discussion. 


\section{Further Modeling Limitations}

Our model is oversimplified compared to the reality of an impact into a heterogeneous target. The iSALE hydrocode is not able to accommodate compositional, structural, and material strength variations in target rocks characteristic of sedimentary sequences. Sedimentary rocks are complex and heterogeneous. Wilshire et al. (1972) describe some strata as bedded and others as massive, as well as thin sandstone, shale, and conglomeratic lithologies in addition to the carbonates. Grain size and the type/degree of cementation between the grains is also variable. All these things are likely to affect the mechanical behavior of the target rocks. iSALE is only able to model three homogenous material layers. Incorporating the strength variations observed within the target stratigraphy into the hydrocode may produce modeled results more in agreement with the observed geology. Not only might the distribution of deformation more accurately reflect the geology, but the problem with the overturned strata in the model may be eliminated. Of course, the resolution of our models places limits on how thin a material layer can be and still be well resolved. Even if our hydrocode were able to accommodate multiple material layers, just considering the scale of bedding planes (e.g., bedding within the Gilliam Limestone ranges from a few centimeters to a couple meters in thickness [Wilshire et al. 1972]), our current cell size of $25 \mathrm{~m}$ is insufficient to model the observed strength variations within the target sequence.

\section{CONCLUSIONS}

We have reproduced the major geologic features and many details of the Sierra Madera structure through numerical modeling. Both of our best-fitting models yield generally good fits to the observed Sierra Madera structure. The best-fit model with respect to the current pressure and deformation estimates agrees with previous estimates of a $12 \mathrm{~km}$ rim diameter crater. These diameter estimates assume a direct link between the apparent crater diameter and rim diameter, which is a poor assumption as in many eroded terrestrial structures the apparent crater is associated with a ring of normal faults outside the now eroded rim; based on previous impact deformation mapping at Sierra Madera, this would suggest a rim diameter less than $12 \mathrm{~km}$.

Regardless, a crater with a $12 \mathrm{~km}$ rim diameter (or smaller) does not seem to experience a vigorous enough collapse to account for all the features observed at Sierra Madera, but improvements to the material model are still needed before we reject this crater size. The best overall fit to the crater morphology, in particular the large central uplift, appears to require an original crater diameter several kilometers larger than previously reported. If this is correct, we predict a gravity anomaly and seismic velocities consistent with a $16 \mathrm{~km}$ diameter crater, maximum peak pressures $>40 \mathrm{GPa}$, few overturned strata, and significant deformation outside the current limit of recognized deformation, predictions that can be tested by further field and geophysical studies. Observational and numerical studies can be effectively combined: geologic observations have been used to evaluate the numerical models, and in turn the model results suggest new observational tests.

Despite the simplicity of the iSALE hydrocode, we were able to simulate the major features of Sierra Madera. However, several improvements to the hydrocode are required for more accurate modeling of sedimentary target rock deformation. We have shown that modeled shock pressures are quite dependent on both target porosity and impact velocity. Lower impact velocities and/or higher porosities result in significantly smaller amounts of highly shocked rocks, but the peak pressures still exceed the observed range at Sierra Madera. In the future, we hope to incorporate a more appropriate equation of state and further refine our strength model to incorporate characteristics of sedimentary sequences, such as pore saturation and the existence of bedding planes.

The Sierra Madera impact structure has received little attention since the early 1970s and it is our hope that the questions raised by this study will spark new interest in Sierra Madera. Additionally, we hope that this study draws attention to the limitations of current hydrocodes in models of impacts into sedimentary targets. Improvements to the hydrocodes, as well as simulations of other impacts into sedimentary target rocks, will increase understanding of the role sedimentary lithologies play in impact crater formation.

Acknowledgments-This work was supported by NASA grant NAG5-11493 and NSF grant OCE-0220474. The authors thank Natalia Artemieva and Gordon Osinski for their helpful reviews and Boris Ivanov for his assistance in the development of iSALE.

\section{Editorial Handling-Dr. Elisabetta Pierazzo}

\section{REFERENCES}

Amsden A. A., Ruppel H. M., and Hirt C. W. 1980. SALE: A simplified ALE computer program for fluid flows at all speeds. Report \#LA-8095. Los Alamos, New Mexico: Los Alamos National Laboratories. $101 \mathrm{p}$.

Artemieva N., Krap T., and Milkereit B. 2004. Investigating the Lake Bosumtwi impact structure: Insight from numerical modeling. Geochemistry Geophysics Geosystems 5, doi:10.1029/ 2004GC000733.

Bjork R. L. 1961. Analysis of the formation of Meteor Crater, Arizona: A preliminary report. Journal of Geophysical Research 66:3379-3387.

Bottke W. F., Jr., Nolan M. C., Greenberg R., and Kolvoord R. A. 1994. Collisional lifetimes and impact statistics of near-Earth asteroids. In Hazards due to comets and asteroids, edited by Gehrels T. Tucson, Arizona: The University of Arizona. pp. 337-357.

Collins G. S. and Wünnemann K. 2005. How big was the Chesapeake Bay impact? Insight from numerical modeling. Geology 33:925928.

Collins G. S., Melosh H. J., Morgan J. V., and Warner M. R. 2002. 
Hydrocode simulations of Chicxulub crater collapse and peakring formation. Icarus 157:24-33.

Collins G. S., Melosh H. J., and Ivanov B. A. 2004. Modeling damage and deformation in impact simulations. Meteoritics \& Planetary Science 39:217-231.

Crawford D. A. and Barnouin-Jha O. S. 2004. Computational investigations of the Chesapeake Bay impact structure (abstract \#1757). 35th Lunar and Planetary Science Conference. CD-ROM.

Dienes J. K. and Walsh J. M. 1970. Theory of impact: Some general principles and the method of eulerian codes. In High-velocity impact phenomena, edited by Kinslow R. New York: Academic Press. pp. 46-104.

French B. M. 1998. Traces of catastrophe: A handbook of shockmetamorphic effects in terrestrial meteorite impact structures. Houston, Texas: Lunar and Planetary Institute. 120 p.

Fredrich J. T., Evans B., and Wong T. 1990. Effect of grain size on brittle and semi-brittle strength: Applications for micromechanical modelling of failure in compression. Journal of Geophysical Research 95:10,907-10,920.

Grieve R. A. F. and Cintala M. J. 1992. An analysis of differential impact melt-crater scaling and implications for the terrestrial impact record. Meteoritics 27:526-538.

Grieve R. A. F., Langenhorst F., and Stöffler D. 1996. Shock metamorphism of quartz in nature and experiment II: Significance in geoscience. Meteoritics \& Planetary Science 31: 6-35.

HörzF. 1968. Statistical measurements of deformation structures and refractive indices in experimentally shock-loaded quartz. In Shock metamorphism of natural minerals, edited by French B. M. and Short N. M. Baltimore: Mono Book Corporation. pp. 243-353.

Howard K. A., Offield T. W., and Wilshire H. G. 1972. Structure of Sierra Madera, Texas, as a guide to central peaks of lunar craters. Geological Society of America Bulletin 83:2795-2808.

Huson S. A., Foit F. F., Watkinson A. J., and Pope M. C. 2006. X-ray diffraction powder patterns and thin section observations from the Sierra Madera impact structure (abstract \#2377). 37th Lunar and Planetary Science Conference. CD-ROM.

Ivanov B. A. 2005. Numerical modeling of the largest terrestrial meteorite craters. Solar System Research 39:381-409.

Ivanov B. A. and Artemieva N. A. 2002. Numerical modeling of the formation of large impact craters. In Catastrophic events and mass extinctions: Impact and beyond. Washington, D.C.: Geological Society of America. pp. 619-630.

Ivanov B. A., de Niem D., and Neukum G. 1997. Implementation of dynamic strength models into 2D hydrocodes: Applications for atmospheric break-up and impact cratering. International Journal of Impact Engineering 17:375-386.

Ivanov B. A., Langenhorst F., Deutsch A., and Hornemann U. 2002. How strong was impact-induced $\mathrm{CO}_{2}$ degassing in the $\mathrm{K} / \mathrm{T}$ event? Numerical modeling of shock recovery experiments. In Catastrophic events and mass extinctions: Impact and beyond. Washington, D.C.: Geological Society of America. pp. 587-594.

Kenkmann T., Jahn A., Scherler D., and Ivanov B. A. 2005. Structure and formation of a central uplift: A case study at the Upheaval Dome impact crater, Utah. In Large meteorite impacts III, edited by Kenkmann T., Hörz F., and Deutsch A. Washington, D.C.: Geological Society of America. pp. 85-115.

Lockner D. A. 1995. Rock failure. In Rock physics and phase relations: A handbook of physical constants, edited by Ahrens T. J. Washington, D.C.: American Geophysical Union. pp. 127147.

Lundborg N. 1968. Strength of rock-like materials. International Journal of Rock Mechanics and Mining Sciences 5:427-454.
Melosh H. J. 1979. Acoustic fluidization: A new geologic process? Journal of Geophysical Research 84:7513-7520.

Melosh H. J. 1989. Impact cratering: A geologic process. New York: Oxford University Press. 245 p.

Melosh H. J. and Ivanov B. A. 1999. Impact crater collapse. Annual Review of Earth and Planetary Science 27:385-415.

Müller W. F. and Defourneaux M. 1968. Deformationsstrukturen in Quartz als Indikator für Stosswellen: Eine experimentelle Untersuchung an Quartz-Einkristallen. Zeitschrift für Geophysik 34:483-504.

Osinski G. R. and Spray J. G. 2005. Tectonics of complex crater formation as revealed by the Haughton impact structure, Devon Island, Canadian High Arctic. Meteoritics \& Planetary Science 40:1813-1834.

Osinski G. R., Lee P., Spray J. G., Parnell J., Lim D. S. S., Bunch T. E., Cockell C. S., and Glass B. 2005. Geological overview and cratering model for the Haughton impact structure, Devon Island, Canadian High Arctic. Meteoritics \& Planetary Science 40: 1759-1776.

Pierazzo E. and Collins G. 2003. A brief introduction to hydrocode modeling of impact cratering. In Submarine craters and ejectacrater correlation, edited by Claeys P. and Henning D. New York: Springer. pp. 323-340.

Roddy D. J. and Davis L. K. 1977. Shatter cones formed in largescale experimental explosion craters. In Impact and explosion cratering: Planetary and terrestrial implications, edited by Roddy D. J., Pepin R. O., and Merrill R. B. New York: Pergamon. pp. 715-750.

Roddy D. J., Schuster S. H., Kreyenhagen K. N., and Orphal D. L. 1980. Computer code simulations of the formation of Meteor Crater, Arizona: Calculations MC-1 and MC-2. Proceedings, 11th Lunar and Planetary Science Conference. pp. 2275-2308.

Schmidt R. M. and Housen K. R. 1987. Some recent advances in the scaling of impact and explosion cratering. International Journal of Impact Engineering 5:543-560.

Shuvalov V., Ormö J., and Lindström M. 2005. Hydrocode simulation of the Lockne marine target impact event. In Impact tectonics, edited by Koeberl C. and Henkel H. New York: Springer. pp. 405-422.

Tillotson J. M. 1962. Metallic equation of state for hypervelocity impact. General Atomic Report \#GA-3216. San Diego, California: Advanced Research Project Agency. 141 p.

Turtle E. P., Pierazzo E., Collins G. S., Osinski G. R., Melosh H. J., Morgan J. V., and Reimold W. U. 2005. Impact structures: What does crater diameter mean? In Large meteorite impacts III, edited by Kenkmann T., Hörz F., and Deutsch A. Washington, D.C.: Geological Society of America. pp. 1-24.

Wilshire H. G., Offield T. W., Howard K. A., and Cummings D. 1972. Geology of the Sierra Madera cryptoexplosion structure, Pecos County, Texas. U.S. Geological Survey Professional Paper \#599-H. 42 p.

Wünnemann K. and Ivanov B. A. 2003. Numerical modeling of the impact crater depth-diameter dependence in an acoustically fluidized target. Planetary and Space Sciences 51:831-845.

Wünnemann K., Morgan J. V., and Jödicke H. 2005. Is Ries crater typical for its size? An analysis based on old and new geophysical data and numerical modeling. In Large meteorite impacts III, edited by Kenkmann T., Hörz F., and Deutsch A. Washington, D.C.: Geological Society of America. pp. 67-83.

Wünnemann K., Collins G. S., and Melosh H. J. 2006. A strain-based porosity model for use in hydrocode simulations of impacts and implications for transient crater growth in porous targets. Icarus 180:514-527.

Van Lopik J. R. and Geyer R. A. 1963. Gravity and magnetic anomalies of the Sierra Madera, Texas, "dome." Science 142:45-47. 